\title{
EIGHTH REGIONAL MEETING OF ARAB RED CROSS AND RED CRESCENT SOCIETES
}

This Regional Conference, from 4 to 8 April 1976 in Damascus, organized by the Syrian Red Crescent, was chaired by Professor Ahmed Chawkat Chatti, president of the Syrian Red Crescent. It was attended by delegates from the National Societies of Algeria, Bahrein, Egypt, Jordan, Kuwait, Lebanon, Libya, Mauritania, Morocco, People's Democratic Republic of Yemen, Saudi Arabia, Sudan, Syria, Tunisia, United Arab Emirates and the Yemen Arab Republic. Also represented were the "Palestinian Red Crescent"; the Permanent Secretariat of the Arab National Societies; the League of Red Cross Societies whose delegation was led by Mr. H. Beer, Secretary General; and the ICRC, by Mr. M. Naville, member and former President of the ICRC, accompanied by several of the institution's senior officials. The Henry Dunant Institute delegated Mr. P. Gaillard, advisor to the ICRC, to deputize for Mr. J. Pictet, the institute's director, who could not absent himself from Geneva.

During the opening meeting the President of the Syrian Arab Republic delivered an address of welcome. Mr. Naville apologised for for the absence of the ICRC's President, whose message he read out to the meeting:

When they joined the International Red Cross family, the Arab Red Crescent and Red Cross Societies did not come empty-handed: they contributed the fruits of $a$ wisdom and a religion which proclaimed the value of human dignity. Several of the principles on which the Red Cross is based are to be found in the Koran which recognizes and affirms the duty to respect one's neighbour and treat him with justice, whether he be friend or foe.

The ICRC, pursuant to the mandate assigned to it by the International Community, every day protects and assists victims of conflicts. It hopes that the outcome of the Diplomatic Conference in Geneva-the ratification 
of the Protocols Additional to the 1949 Geneva Conventions-will make its action more effective, particularly for the civilian victims of conflicts. It reminds States that without their strict application of the Conventions, its task would be difficult if not impossible.

Like your Societies, the ICRC desires to work for lasting peace which does not countenance injustice. It wishes to promote understanding among the peoples and develop among youth the Red Crescent and Red Cross ideal, a factor of friendship and rapprochement.

Sharing one of your concerns, the ICRC for the last five years has made a systematic effort to translate and publish in Arabic books and documents relating to the Red Crescent and the Red Cross. Fifteen such publications have already appeared. We are gratified that we can report the success of this initiative and the favourable welcome received by the publications in your National Societies, to whom we owe a debt of thanks for their valuable assistance.

The agenda included a number of items which had been previously discussed at other meetings and a number which were new. One of these was co-operation among the League, the ICRC, and the permanent secretariat of the Arab Societies. In that connection, the problem of disseminating knowledge of the Conventions was mentioned and the need, to that end, both to train officials able to ensure such diffusion and to supply National Societies with the appropriate publications and technical means.

Several resolutions and recommendations emerged from the proceedings. Some of these dealt with the support granted to the "Palestinian Red Crescent"; help to the victims of events in Lebanon; the ICRC operations in the territories occupied by Israel; the organization of training institutes in co-operation with the League; and the efforts asked of Arab Societies to disseminate the Geneva Conventions among the armed forces and in schools and universities with assistance from the ICRC. Finally, we would mention a recommendation that the secretariat of the Arab Societies, the National Societies concerned and the Henry Dunant Institute should organize a seminar on the parallel between Islamic principles and those of the Red Cross, Red Crescent and Red Lion and Sun, the reporting on results being assigned to the Henry Dunant Institute.

It was agreed that the next regional meeting would be organized by the Moroccan Red Crescent and held in Rabat in 1977. 